Pacific Journal of Mathematic 


\section{UNIQUENESS THEOREMS FOR TAUT SUBMANIFOLDS}

\section{Michael Freedman}

1. Introduction and statements of theorems. Given two closed smooth manifolds, how do you tell if they are diffeomorphic? If you start out with a homotopy equivalence, Browder-Novikoff Theory breaks the problem up into: (1) finding all self-equivalences, (2) finding a normal bordism, and (3) the surgery obstruction on the normal bordism. In applications, however, one may encounter manifolds suspected of being diffeomorphic, where no obvious homotopy equivalence is present.

We describe such a situation: Let $\left.\right|_{M} ^{\zeta}$ be a simply connected, finite, simplicial complex with linear bundle. Let $K_{t}^{2 n} \stackrel{f_{i}}{\rightarrow} M, i=0$ or $1, n \geqq 3$, be normal maps from closed smooth manifolds, i.e. $f_{i}^{*}(\zeta)=\nu\left(K_{i}\right)$ : Suppose that $f_{1}$ and $f_{2}$ are normally bordant, $f_{i}$ is $n$-connected, and that $B_{n}\left(K_{0}\right)=B_{n}\left(K_{1}\right) . B_{n}$ here denotes the $n$-th Betti number. It follows from Poincaré's Duality and the universal coefficient theorem that $K_{0}$ and $K_{1}$ have isomorphic integral homology groups, but a map inducing this isomorphism is lacking. However,

THEOREM 1. If $n$ is odd, $K_{0}$ and $K_{1}$ are diffeomorphic.

THEOREM 2. If $n$ is even, but not 2 , and the intersection pairings on

$$
\begin{aligned}
& \left(\operatorname{Ker} f_{0}: H_{n}\left(K_{0} ; Z\right) \rightarrow H_{n}(M ; Z)\right) / \text { torsion and } \\
& \left(\operatorname{Ker} f_{1}: H_{n}\left(K_{1} ; Z\right) \rightarrow H_{n}(M ; Z)\right) / \text { torsion }
\end{aligned}
$$

are isometric and nonsingular, then $K_{0}$ and $K_{1}$ are diffeomorphic.

Corollary 1. If $M^{2 n+2}$ is a compact, simply connected, smooth $2 n+2$-manifold, $n$ odd, and $K_{0}^{2 n} \stackrel{\iota_{0}}{\rightarrow} M^{2 n+2}$ and $K_{1}^{2 n} \stackrel{l_{1}}{\rightarrow} M^{2 n+2}$ are $n$ connected inclusions of closed submanifolds with $i_{0^{*}}\left[K_{0}\right]=$ $i_{1} \cdot\left[K_{1}\right] \in H_{2 n}\left(M^{2 n+2} ; Z\right)$, then if $B_{n}\left(K_{0}\right)=B_{n}\left(K_{1}\right), K_{0}$ is diffeomorphic to $K_{1}$.

COROLlARY 2. Assume $M^{2 n+2}$ is a simply connected smooth $2 n+2-$ manifold, $n$ even $(n \neq 2)$, with $H_{n}(M ; Z)=0$. If $i_{0}$ and $i_{1}$ are as above, then if the intersection pairings on $H_{n}\left(K_{0} ; Z\right) /$ torsion and $H_{n}\left(K_{1} ; Z\right) /$ torsion are isometric, $K_{1}$ is diffeomorphic to $K_{2}$.

REMARK 1. The above corollaries are specialized by replacing the 
connectivity assumptions with the assumption that the submanifolds are taut (definition: $\pi_{i}(M$-neighborhood $\left.(K), \partial)=0, i \leqq n\right)$.

REMARK 2. It follows from Corollary 1 and [2] that if $n$ is odd and $\pi_{1}\left(M^{2 n+2}\right)=0$, every homology class $X \in H_{2 n}\left(M^{2 n+2} ; Z\right)$ is represented by a simplest submanifold with an $n$-connected inclusion map, $K^{0}$, and every other submanifold with an $n$-connected inclusion map is diffeomorphic to $K^{t}=K^{0} \underbrace{\# S^{n} \times S^{n} \times \# \cdots \# S^{n} \times S^{n}}, t \geqq 0$.

$t$-copies

THEOREM 3. If $\pi_{1}\left(M^{2 n+2}\right)=0$, and if $K_{0}$ and $K_{1}$ are submanifolds representing $X \in H_{2 n}\left(M^{2 n+2} ; Z\right)$ with $n$-connected inclusion maps, then there are integers $j, k$ such that $K_{0} \# S^{n} \times S^{n} \# \cdots \# S^{n} \times S^{n}$ is diffeomor-

phic to $K_{1} \underbrace{\# S^{n} \times S^{n} \# \cdots \# S^{n} \times S^{n}}_{k \text {-copies }}$.

$$
j \text {-copies }
$$

2. Proofs. (All coefficients will be integral unless stated.) Thm $1 \Rightarrow$ Cor 1 and Thm $2 \Rightarrow$ Cor 2: Let $N$ be a very large integer. $i: C P^{N-1} \rightarrow C P^{N}$ is an isomorphism on $H_{2}(; Z)$ so there is a unique 2-plane bundle $\int_{C P^{N}}^{\zeta}$ extending $\nu_{C P^{N-1} \rightarrow C P^{N}}$. Since $i_{1 \cdot} \cdot\left[K_{1}\right]=i_{2^{*}}\left[K_{2}\right]$, there is a homotopy $h: M \times I \rightarrow C P^{N}$ with $h_{0}^{-1}\left(C P^{N-1}\right)=K_{0}$ and $h_{1}^{-1}\left(C P^{N-1}\right)=$ $K_{1}$. $\quad h^{*}(\zeta)$ extends $\nu_{K_{0} \times 0 \rightarrow M \times 0}$ and $\nu_{K_{1} \times 1 \rightarrow M \times 1}$. Furthermore, the inclusions $K_{0} \times\left. 0 \rightarrow\right|_{M \times 0} ^{\nu(M) \oplus h^{*}(\zeta)}$ and $K_{1} \times\left. 1 \rightarrow\right|_{M \times 1} ^{\nu(M) \oplus h^{*}(\zeta)}$ are normal maps and if $h$ is transverse to $C P^{N-1}, h^{-1}\left(C P^{N-1}\right)$ provides a normal bordism. This together with the hypothesis of Corollary 1 (or Corollary 2) is the hypothesis of Theorem 1 (or Theorem 2). Corollary 1 (or Corollary 2) follows.

Proof of Theorem 1. Let $L, \partial L=K_{0} \cup-K_{1}$, be a normal bordism. By Theorem 1.2 [4] we may assume $f: L \rightarrow M$ is $n$ connected. It follows that $H_{*}\left(L, K_{0}\right)=0$ for $* \neq n, n+1$. Our plan is to perform some normal $n$-surgery on interior $(L)$ to produce $L^{\prime}$ with $H_{n}\left(L^{\prime}, K_{0}\right)=0$ (this will leave $H_{*}\left(L, K_{0}\right)$ unchanged $\left.* \leqq n-1\right)$. By duality and U.C.T. $H_{*}\left(L^{\prime}, K_{0}\right)=0$, and $L \stackrel{\text { diff }}{\cong} K_{0} \times I \Rightarrow K_{1} \stackrel{\text { diff }}{\cong} K_{0}$ by the $h$-cobordism theorem.

Let $i_{0}: K_{0} \rightarrow L$ and $i_{1}: K_{1} \rightarrow L$ be the inclusions. Consider the following commutative diagram: 




Since $f_{0}$ factors through $i_{0}, \operatorname{coker}\left(f_{0_{n+1}}\right) \stackrel{\text { id. }}{\rightarrow} \operatorname{coker}\left(f_{n+1}\right)$ is epi. There is a short exact sequence

$$
\begin{gathered}
0 \rightarrow \operatorname{coker}\left(f_{n+1}\right) / \operatorname{coker}\left(f_{0_{n+1}}\right) \\
\mathbb{\|} \\
0
\end{gathered}
$$

so there is a natural isomorphism

$$
\operatorname{Ker} f_{n_{i_{i} 0^{*}\left(\text { Ker }_{0_{n}}\right)^{\prime}}} \cong H_{n}\left(L, K_{0}\right) \text {. }
$$

We will consider the two modules identified.

Duality and the U.C.T. show $H_{n}\left(L, K_{0}\right)$ and $H_{n}\left(L, K_{1}\right)$ are isomorphic. So we have a noncommutative diagram:



We need an algebraic fact about such diagrams.

LEMMA 1. If $F$ is a field, there are elements $a_{1}, \cdots, a_{k} \in A$, such that $\left\{\pi_{\epsilon}\left(a_{1}\right) \otimes 1, \cdots, \pi_{\epsilon}\left(a_{k}\right) \otimes 1\right\}$ is a basis for $C_{\epsilon} \otimes z F, \epsilon=0$ or 1 .

Proof. By induction. $\operatorname{dim}_{F}\left(C_{0} \otimes_{z} F\right)=\operatorname{dim}_{F}\left(C_{1} \otimes_{z} F\right)$. Suppose $a_{1} \cdots a_{j}$ are already chosen so that $\pi_{\epsilon}\left(a_{1}\right) \otimes 1, \cdots, \pi_{\epsilon}\left(a_{j}\right) \otimes 1$ are independent. Let the spans of these vectors be $\operatorname{span}_{j, 0}$ and $\operatorname{span}_{j, 1}$. If these spans are proper subspaces of $C_{0} \otimes_{z} F$ and $C_{1} \otimes_{z} f$, then $\pi_{\epsilon}^{-1}\left(\operatorname{span}_{j, \epsilon}\right)$ are proper subspaces of $A \otimes_{z} F$. Let $a_{\jmath+1}$ be any element of $A$ such that $a_{l+1} \otimes 1 \in\left(A \otimes_{z} F-\left(\bigcup_{\epsilon=0,1} \pi_{\epsilon}^{-1}\left(\operatorname{span}_{j, \epsilon}\right)\right)\right) \neq \varnothing$.

In order to compute the effect on $H_{n}\left(L, K_{0}\right)$ of normal $n$-surgeries along $L$, we use a diagram adapted from Lemma IV.3.2 [1]. (At this 
point it may be helpful for the reader to review the proof that the odd dimensional simply connected surgery obstruction vanishes, see Ch. IV, $\S 3$ of [1]. This argument is originally due to J. Milnor and M. Kervaire, see [3].)

LEMMA 2. If $L^{\prime}$ results from a normal surgery on $S^{n} \hookrightarrow L,\left[S^{n}\right]=$ $x \in \operatorname{ker} f_{n}$, we have the following diagram:

$$
\begin{aligned}
& H_{n+1}\left(L^{\prime}, K_{0}\right) \\
& Z \in \lambda^{\prime} \\
& \pi_{1}(x) \cdot \quad d^{\prime} \\
& H_{n+1}\left(L, K_{0}\right) \stackrel{\pi_{1}(x) \cdot}{\theta} Z \stackrel{d}{\longrightarrow} H_{n}\left(L_{0}, K_{0}\right) \stackrel{i_{*}}{\longrightarrow} H_{n}\left(L, K_{0}\right) \longrightarrow 0 \\
& \downarrow i_{*}^{\prime} \\
& H_{n}\left(L^{\prime}, K_{0}\right) \\
& \downarrow \\
& 0
\end{aligned}
$$

with: (1) $\pi_{0}(x)=x_{0}=i_{*} d\left(\lambda^{\prime}\right)$, where $\lambda^{\prime}$ is the appropriate generator above. (2) The map $\theta: H_{n+1}\left(L, K_{0}\right) \rightarrow Z$ is given by intersection with $\pi_{1}(x) \in H_{n}\left(L, K_{1}\right)$.

Proof. (1) See Lemma IV.3.2 [1].

(2) $\theta: H_{n+1}\left(L, K_{0}\right) \rightarrow Z$ may be thought of as:

$$
H_{n+1}\left(L / K_{0}\right) \stackrel{j}{\rightarrow} H_{n+1}\left(L / K_{0}, L_{0} / K_{0}\right) \stackrel{\operatorname{exc}^{-1}}{\longrightarrow} H_{n+1}\left(S^{n} \times D^{n+1}, S^{n} \times S^{n}\right) \stackrel{U(~}{\longrightarrow} Z
$$

where the last map is evaluation of the Thom class $U \in$ $H^{n+1}\left(S^{n} \times D^{n+1}, S^{n} \times S^{n}\right) . \quad$ Let $\quad a \in H_{n+1}\left(L / K_{0}\right) . \quad j^{*}\left(\operatorname{exc}^{-1} U\right)(a)=$ $U\left(\bar{J}_{*} a\right)=\theta(a)$.

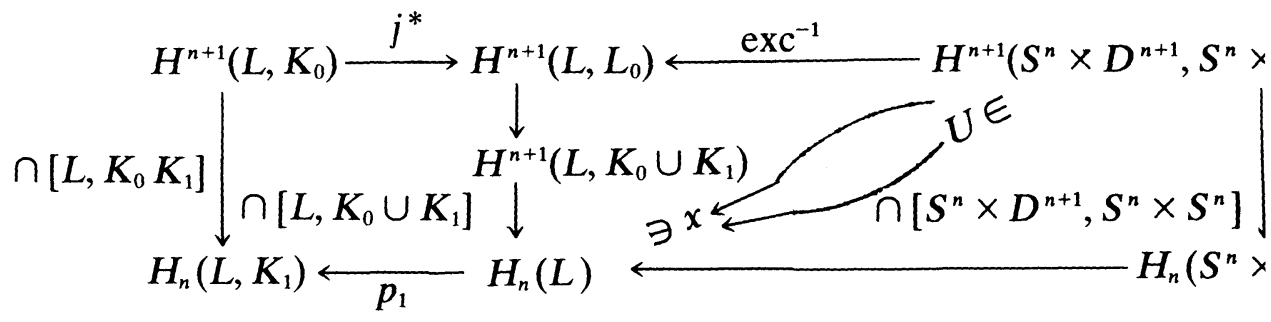

$j^{*}\left(\operatorname{exc}^{-1} U\right) \cap\left[L, K_{0} \cup K_{1}\right]=\pi_{1}(x) \in H_{n}\left(L, K_{1}\right)$, so 


$$
\theta(a)=j^{*}\left(\operatorname{exc}^{-1} U\right)(a)=\pi_{1}(x) \cdot(a)
$$

where $\cdot$ denotes algebraic intersection.

LEMMA 3. If we set $y=i_{*}^{\prime} d(\lambda)$, then: by".

(1) $H_{n}\left(L^{\prime}, K_{0}\right) /\langle y\rangle \cong H_{n}\left(L, K_{0}\right) /\left\langle x_{0}\right\rangle,\langle\rangle$ means "subgroup generated

(2) Suppose $\left(x_{0}\right)$ has finite order $s$, then for some $t \in Z s d^{\prime}\left(\lambda^{\prime}\right)+$ $t d(\lambda)=0$. Order $(y)=\infty$ iff $t=0$. Order $y=t$ iff $t \neq 0$.

(3) If $n$ is even (as in Theorem 2), $t=0$.

(4) If $n$ is odd (as in Theorem 1), $L^{\prime}$ is not uniquely determined, and may be varied to $L_{m}^{\prime}$ by changing the framing of the surgery along $x$ by $m$ times the generator of $\operatorname{ker}\left(\pi_{n}(S O(n+1)) \rightarrow \pi_{n}(S O)\right) \cong Z$. So $t$ is a function of $L_{m}^{\prime}$. We have the relation: $t\left(L_{m}^{\prime}\right)=t\left(L^{\prime}\right)+2 m s$.

Proof. These facts correspond to Lemmas 3.2, 3.5, 3.8 and 3.11 respectively in Chapter IV of [1].

LEMMA 4. $\left.\quad L^{2 n} \rightarrow\right|_{M} ^{\xi}$ is normally bordant rel $\partial$ to $L^{\prime}$ satisfying $H_{*}\left(L^{\prime}, K_{0}\right)=0, * \leqq n-1$ and $H_{n}\left(L^{\prime}, K_{0}\right)=$ torsion. (This lemma holds for $n$ even or odd.)

Proof. In Lemma 1 set $F=Q$, normal surgery on the classes $\left\{a_{1}, \cdots, a_{k}\right\}$ affords the desired $L^{\prime}$. More precisely, assume $\operatorname{Rank}_{Z}\left(H_{n}\left(L, K_{0}\right)\right)>0$. By setting $F=Q$ and $a_{1}=x$ in Lemma $1, \pi_{0}(x)=$ $x_{0}$ and $\pi_{1}(x)=x_{1}$ are infinite order. Therefore, by diagram $(*)\left\langle x_{0}\right\rangle=Z$ and $\langle y\rangle=$ torsion. Let $L^{\prime}$ result from surgery on $x$. Now (1) of Lemma 3 implies $\operatorname{Rank}_{Z}\left(H_{n}\left(L^{\prime}, K_{0}\right)\right)=\operatorname{Rand}_{Z}\left(H_{n}\left(L, K_{0}\right)\right)-1$. Proceed inductively.

REMARK 3. It may not be possible to do the preceding construction without increasing the order of torsion $\left(H_{n}\left(L, K_{0}\right)\right)$. The reason is that there are diagrams, for example:



so that $\nexists x \in Z+Z$ with $\pi_{\epsilon}(x)$ generating a free summand. So unlike the classical case, killing the free part may increase the torsion!

LeMMA 4'. Given a prime, $p,\left.L^{2 n} \rightarrow\right|_{M} ^{\xi}$ is normally bordant rel $\partial$ to $L^{\prime}$ such that $H_{*}\left(L^{\prime}, K_{0}\right)=0, * \leqq n-1$, and $H_{n}\left(L^{\prime}, K_{0}\right) \otimes Z_{p}=0$. (This lemma holds for $n$ even or odd.) 
Proof. Assume $L$ satisfies the conclusion of Lemma 4. In Lemma 1 set $F=Z_{p}$ and $a_{1}=x$. Now consider diagram $(*)$ with $Z_{p}$ coefficient. The $\bmod p$ reductions $\left(\pi_{0}(x)\right)_{p}=\left(x_{0}\right)_{p} \in H_{n}\left(L, K_{0} ; Z_{p}\right)$ and $\left(\pi_{1}(x)\right)_{p}=$ $\left(x_{1}\right)_{p} \in H_{n}\left(L, K_{1} ; Z_{p}\right)$ are nonzero. $d$ is the zero map so by (1) of Lemma 3:

$$
\operatorname{Rank}_{Z_{p}}\left(H_{n}\left(L, K_{0} ; Z_{p}\right)\right)=\operatorname{Rank}_{Z_{p}}\left(H_{n}\left(L^{\prime}, K_{0}\right) ; Z_{p}\right)+1 .
$$

Using the U.C.T. and $H_{n+1}\left(L^{(\prime)}, K_{0} ; Z\right)=0$ we have:

$$
\operatorname{Rank}_{Z_{p}}\left(H_{n}\left(L, K_{0} ; Z\right) \otimes Z_{p}\right)=\operatorname{Rank}_{Z_{p}}\left(H_{n}\left(L^{\prime}, K_{0}\right) \otimes Z_{p}\right)+1 .
$$

Lemma $4^{\prime}$ now follows by induction on the above rank.

The argument is now restricted to $n=$ odd. The prime 2 will play a special role.

Let $L$ satisfy $H_{*}\left(L, K_{0}\right)=0, * \leqq n-1$ and $H_{n}\left(L, K_{0}\right) \otimes Z_{2}=0$ (i.e., $H_{n}\left(L, K_{0}\right)$ is odd torsion).

LEMMA 5. If $n$ is odd and $L$ is as above, and if a prime p/order $\left(H_{n}\left(L, K_{0}\right)\right)$ there is a normal bordism rel $\partial L$ to $L^{\prime}$ (consisting of either one or two normal $n$-surgeries) with: (1) $H_{*}\left(L^{\prime}, K_{0}\right)=0, * \leqq n-1$, (2) $H_{n}\left(L^{\prime}, K_{0}\right)$ odd torsion, and either: (3) order $H_{n}\left(L^{\prime}, K_{0}\right) \leqq$ order $H_{n}\left(L, K_{0}\right)$, and (4) $\left.\operatorname{Rank}_{Z_{p}}\left(H_{n}\left(L^{\prime}, K_{0}\right) \otimes Z_{p}\right)<\operatorname{Rank}_{Z_{p}}\left(H_{n}\left(L, K_{0}\right) \otimes Z_{p}\right)\right)$ or $\left(3^{\prime}\right)$ order $H_{n}\left(L^{\prime}, K_{0}\right)<$ order $H_{n}\left(L, K_{0}\right)$.

Proof. In Lemma 1 set $F=Z_{p}$ and $a_{1}=x$. As in the proof of Lemma 4', any normal surgery based on $x$ results in an $L^{\prime}$ with $\operatorname{Rank}_{Z_{p}}\left(H_{n}\left(L^{\prime}, K_{0}\right) \otimes Z_{p}\right)<\operatorname{Rank}_{Z_{p}}\left(H_{n}\left(L, K_{0}\right) \otimes Z_{p}\right)$. By (4) of Lemma 3 $\forall m, t\left(L_{m}^{\prime}\right)=t\left(L^{\prime}\right)+2 m s$, where $s=$ order $x_{0} \in H_{n}\left(L, K_{0}\right)$. By (1) and (2) of Lemma $3, t\left(L_{m}^{\prime}\right) \neq 0$ iff $H_{n}\left(L_{m}^{\prime}, K_{0}\right)=$ torsion, and order (torsion $\left.H_{n}\left(L_{m}^{\prime}, K_{0}\right)\right) \leqq$ order (torsion $\left.H_{n}\left(L_{m}, K_{0}\right)\right)$ iff $-s \leqq t\left(L_{m}^{\prime}\right) \leqq s$. If (and only if) $t\left(L_{m}^{\prime}\right)=2 s$, order $H_{n}\left(L^{\prime}, K_{0}\right)=2\left(\operatorname{order} H_{n}\left(L, K_{0}\right)\right)$. We may choose $m$ so that: Case A. $t\left(L_{m}^{\prime}\right) \neq 0$ and $-s \leqq t\left(L_{m}^{\prime}\right) \leqq s$ or Case B. $t\left(L_{m}^{\prime}\right)=2 s$.

In each case diagram $(*)$ with $Z_{2}$ coefficients shows $\operatorname{Rank}_{Z_{2}}\left(H_{n}\left(L^{\prime}, K_{0}\right) \otimes Z_{2}\right)=0$ or 1 . In Case $A$ we are finished if the above rank is zero; assume it is one. If $t\left(L_{m}^{\prime}\right)= \pm s$, order $H_{n}\left(L^{\prime}, K_{0}\right)=$ order $H_{n}\left(L, K_{0}\right)$, so (2) and (3) above are satisfied and we are finished. So add the assumption: $-s<t\left(L_{m}^{\prime}\right)<s$. Then order $H_{n}\left(L^{\prime}, K_{0}\right)<$ order $H_{n}\left(L, K_{0}\right)$. Now Lemma 1 with $F=Z_{2}$ provides $x^{\prime}=a_{1} \in \operatorname{ker} f_{n}^{\prime}: H_{n}\left(L^{\prime}\right) \rightarrow H_{n}(M)$, so that if $L^{\prime \prime}$ is the result of a normal surgery on $x^{\prime}$ then $H_{n}\left(L^{\prime \prime}, K_{0}\right) \otimes Z_{2}=0$. $\exists r \in Z$ such that -order $x^{\prime} \leqq t\left(L_{r}^{\prime \prime}\right) \leqq$ order $x^{\prime}$. However, $t\left(L_{r}^{\prime \prime}\right) \neq 0$ as this would imply order $H\left(L_{r}^{\prime \prime}, K_{0}\right)=\infty$, contradicting $H_{n}\left(L_{r}^{\prime \prime}, K_{0}\right) \otimes Z_{2}=0$. So order $\left(H_{n}\left(L_{r}^{\prime \prime}, K_{0}\right)\right)$ $\leqq$ order $\left(H_{n}\left(L_{m}^{\prime}, K_{0}\right)\right)<\operatorname{order}\left(H_{n}\left(L, K_{0}\right)\right)$ so $\left(3^{\prime}\right)$ above is satisfied. This completes Case A. 
In Case B order $\left(H_{n}\left(L_{m}^{\prime}, K_{0}\right)\right)=2\left(\operatorname{order}\left(H_{n}\left(L, K_{0}\right)\right)\right)$.

LEMMA 6. $\exists x^{\prime} \in \operatorname{ker} f_{n}^{\prime}: H_{n}\left(L_{m}^{\prime}\right) \rightarrow H_{n}(M)$ such that $\pi_{0}\left(x^{\prime}\right)$ is the unique element of order $2, \delta$, in $H_{n}\left(L_{m}^{\prime}, K_{0}\right)$ and $\left(\pi_{1}\left(x^{\prime}\right)\right)_{2} \neq 0$.

Proof. $H_{n}\left(L_{m}^{\prime}, K_{0}\right) \cong H_{n}\left(L_{m}^{\prime}, K_{1}\right) \cong Z_{2}+\mathcal{O}$, where $\mathcal{O}$ is odd torsion. Consider compositions $P_{0}, P_{1}$

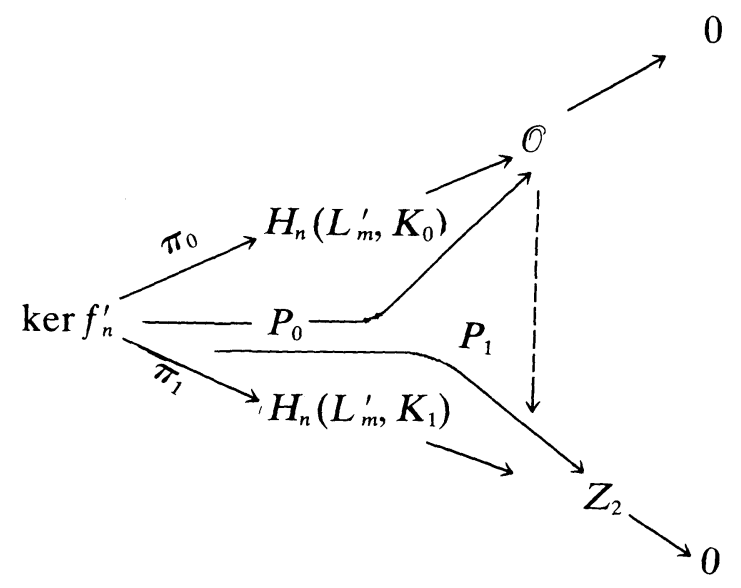

Ker $P_{0} \not \subset$ ker $P_{1}$, otherwise $P_{1}$ could be factored through $P_{0}$ by an epimorphism (dotted arrow). Let $x \in \operatorname{ker} P_{0}-\operatorname{ker} P_{1} . \pi_{0}(x)=0$ or $\delta$, $\left(\pi_{1}(x)\right)_{2} \neq 0$. If $\pi_{0}(x)=\delta$, set $x^{\prime}=x$ and we are finished. If $\pi_{0}(x)=0$ let $y \in \operatorname{ker} f_{n}^{\prime}$ satisfy $\pi_{0}(y)=\delta$. If $\left(\pi_{1}(y)\right)_{2} \neq 0$, set $x^{\prime}=y$ and we are finished. If $\left(\pi_{1}(y)\right)_{2}=0$, set $x^{\prime}=x+y$. Now $\pi_{0}\left(x^{\prime}\right)=\pi_{0}(x+y)=$ $0+\delta=\delta$ and $\left(\pi_{1}\left(x^{\prime}\right)\right)_{2}=\left(\pi_{1}(x+\dot{y})\right)_{2}=\left(\pi_{1}(x)\right)_{2}+\left(\pi_{1}(y)\right)_{2}=1+0=1$.

Let $L_{r}^{\prime \prime}$ be the result of a normal surgery along $x^{\prime}$. Again looking at Rank $_{Z_{2}}$ tells us $t\left(L_{r}^{\prime \prime}\right) \neq 0,2$. Therefore we can choose $r$ so that $t\left(L_{r}^{\prime \prime}\right)=$ \pm 1 . It follows from diagram $(*)$ that $H_{n}\left(L_{r}^{\prime \prime}, K_{0}\right) \cong H_{n}\left(L_{m}^{\prime}, K_{0}\right) / Z_{2} . L_{r}^{\prime \prime}$ satisfies (3) above, but

$$
\operatorname{Rank}_{Z_{p}}\left(H_{n}\left(L_{r}^{\prime \prime}, K_{0}\right) \otimes Z_{p}\right)=\operatorname{Rank}_{Z_{p}}\left(H_{n}\left(L_{m}^{\prime}, K_{0}\right)<\operatorname{Rank}_{Z_{p}}\left(H_{n}\left(L, K_{0}\right)\right)\right.
$$

so $L_{r}^{\prime \prime}$ also satisfies (4) above. This completes Case B.

$\operatorname{Rank}_{Z_{p}}\left(H_{n}\left(L, K_{0}\right) \otimes Z_{p}\right)$ is finite so after a finite number of applications of Lemma 5 , it is no longer possible to reduce the $Z_{p}$-rank without increasing order $\left(H_{n}\left(L, K_{0}\right)\right)$. So we can find a normal cobordism rel $\partial$ of $L$ to $L^{\prime}$ with (1), (2) and (3') satisfied. By inducting on order $\left(H_{n}\left(L, K_{0}\right)\right)$, we have a normal bordism rel boundary to $L^{\prime}$ with $H_{*}\left(L^{\prime}, K_{0}\right)=0$, all values of $*$. Theorem 1 now follows from the $h$-cobordism theorem. 
Proof of Theorem 2. If $n$ is even, surgery on a torsion class of $H_{n}\left(L, K_{0}\right)$ will always increase the $\operatorname{rank}_{z}\left(H_{n}\left(L, K_{0}\right)\right)$ (see Lemma IV.3.8 of [1]). Remark 3 shows that it may be impossible to do surgery to lower $\operatorname{Rank}_{Z}\left(H_{n}\left(L, K_{0}\right)\right)$ without increasing order (torsion $\left.H_{n}\left(L, K_{0}\right)\right)$. This prevents the usual inductive argument on order torsion $H_{n}\left(L, K_{0}\right)$, and is the reason that Theorem 2 requires an additional assumption.

Let $\left\{\alpha_{1}^{0}, \cdots, \alpha_{k}^{0}\right\} \subset \operatorname{ker} f_{0}: \quad H_{n}\left(K_{0}\right) \rightarrow H_{n}(M)$ be a basis for $\left(\operatorname{ker} f_{0} ; Z\right) /$ torsion and let $\left\{\alpha_{1}^{1}, \cdots, \alpha_{k}^{1}\right\} \subset\left(\operatorname{ker} f_{1}, Z\right)$ be the isometric image of $\left\{\alpha_{1}^{0}, \cdots, \alpha_{k}^{0}\right\}$. By the relative Hurewicz Theorem, the $\alpha$ 's are spherical. The classes $\left\{\left(i_{0} .\left(\alpha_{1}^{0}\right)-i_{1} .\left(\alpha_{1}^{1}\right), \cdots, i_{0} .\left(\alpha_{k}^{0}\right)-i_{1} .\left(\alpha_{k}^{1}\right)\right\}\right.$ are represented by framed, imbedded $n$-spheres, $s_{1}, \cdots, s_{k}$. Let $L^{\prime}$ be the result of a normal surgery on $\left\{s_{1}, \cdots, s_{k}\right\}$. Let $h_{0}, h_{1}$ denote the inclusions $K_{0} \rightarrow L^{\prime}, K_{1} \rightarrow L^{\prime}$.

Lemma 7. $h_{0 .}\left(\operatorname{ker} f_{0} ; Z\right)=h_{1} \cdot\left(\operatorname{ker} f_{1} ; Z\right)$ in the quotient $H_{n}\left(L^{\prime} ; Z\right) /$ torsion.

Proof. By induction on the number of surgeries. We will denote the inclusions at any stage by inc $c_{0}$ and inc $c_{1}$. Surgery on $s_{1}$ makes inc $_{0}\left(\alpha_{1}^{0}\right)=$ inc $_{1}\left(\alpha_{1}^{1}\right)$. Assume that after surgery on $s_{1}, \cdots, s_{i}, \operatorname{inc}_{0}\left(\alpha_{i}^{0}\right)=$ $\operatorname{inc}_{1}\left(\alpha_{1}^{1}\right), 1 \leqq i \leqq j$. Let $b_{1}, \cdots, b_{l}$ be simplicial chains with $\partial b_{i}=$ $\alpha_{1}^{0} \cup-\alpha_{1}^{1}$. Let $\pitchfork$ denote algebraic intersection. $\prod_{L}\left(s_{t+1}, b_{1}\right)=$ $\prod_{K_{0}}\left(\alpha_{j+1}^{0}, \alpha_{\imath}^{0}\right)+\prod_{K_{1}}\left(-\alpha_{j+1}^{1}, \alpha_{\imath}^{1}\right)=0$ (using the isometry). As a result, $\operatorname{inc}_{0}\left(\alpha_{l}^{0}\right)$ and $\operatorname{inc}_{1}\left(\alpha_{l}^{1}\right)$ remain equal after surgery on $s_{l+1}$ and $\operatorname{inc}_{0}\left(\alpha_{i+1}^{0}\right)=$ inc $_{1}\left(\alpha_{j+1}^{1}\right)$. The lemma follows.

Consider the following diagram with all kernels interpreted by applying the function $H_{n}(; Z)$.

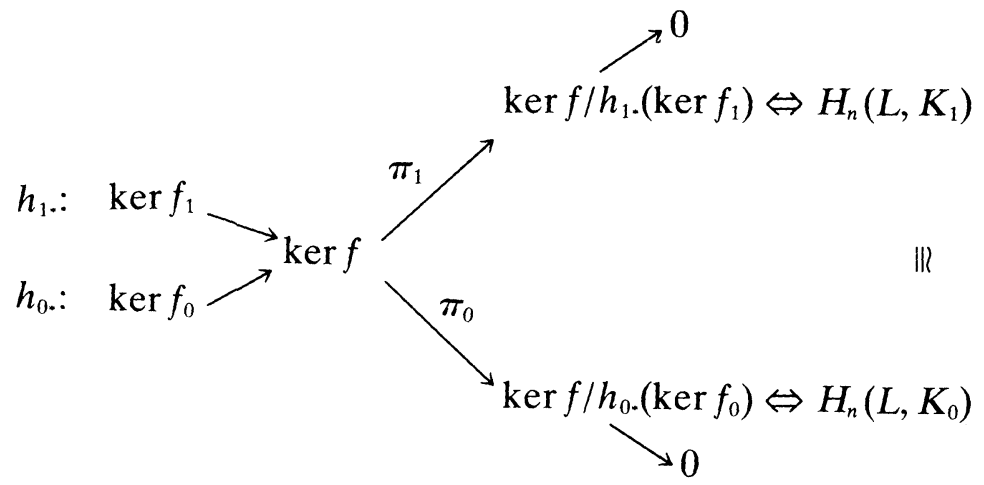

Lemma 7 implies $h_{1}\left(\operatorname{ker} f_{1}\right)=h_{0}\left(\operatorname{ker} f_{0}\right)$ in the quotient $(\operatorname{ker} f) /$ torsion.

Assuming the hypothesis of Theorem 2, we have:

LEMMA 8. Suppose $h_{1} \cdot\left(\operatorname{ker} f_{1}\right)=h_{0} \cdot\left(\operatorname{ker} f_{0}\right)$ in the quotient $(\operatorname{ker} f) /$ torsion. If $\operatorname{Rank}_{Z} H_{n}\left(L, K_{0}\right)>0 \exists x \in \operatorname{ker} f$ such that 
and

(1) $\pi_{\epsilon}(x)=x_{\epsilon}$ generates a free summand of $H_{n}\left(L, K_{\epsilon}\right)$, for $\epsilon=0,1$,

(2) If $L^{\prime}$ is the result of surgery on $x, h_{1} \cdot\left(\operatorname{ker} f_{1}\right)=h_{0} \cdot\left(\operatorname{ker} f_{0}\right)$ in the quotient $\left(\operatorname{ker} f^{\prime}\right) /$ torsion.

(3) $H_{n}\left(L, K_{0}\right) \cong H_{n}\left(L^{\prime}, K_{0}\right) \oplus Z$.

Proof. Let $y \in H_{n}\left(L, K_{0}\right)$ generate a free summand. Let $x^{\prime} \in \operatorname{ker} f$ satisfy $\pi_{0}\left(x^{\prime}\right)=y \cdot \pi_{1}\left(x^{\prime}\right)$ generates a free summand of $H_{n}\left(L, K_{1}\right)$ (Proof: Consider the above diagram modulo torsion.). Let $b_{l}, 1 \leqq i \leqq k$, be as before. Let $a_{t}=\prod\left(x^{\prime}, b_{\imath}\right)$. Since $\left(\operatorname{ker} f_{0 .}, \Pi\right)$ is nonsingular, $\exists \beta \in$ $\operatorname{ker} f_{0}$ such that $\prod_{K_{0}}\left(\beta, \alpha_{\imath}\right)=-a_{\imath} \quad \forall 1 \leqq i \leqq k$. Set $x=x^{\prime}+i_{0}(\beta)$. $\pitchfork\left(x^{\prime}, b_{1}\right)=0 \forall b_{1}$. (2) now follows. It is easy to check (3) using diagram $(*)$ of Lemma 2. (Compare with Remark 3.)

Let $\left(L^{\prime} ; K_{0}, K_{1}\right)$ be a normal bordism satisfying the conclusion of Lemma 7. By virtue of Lemma 8, we may do surgery to eliminate $H_{n}\left(L^{\prime}, K_{0}\right)$. The argument for this coincides with "the proof of Theorem IV.2.1 for $m=2 q+1, q$ even", page 104, [1]. As before, $L^{\prime}$ becomes an $h$-cobordism completing the proof of Theorem 2 .

REMARK 4. If $n=2$, this argument may be used to give another proof of: homotopy equivalence $\Rightarrow h$-cobordism for simply connected 4-manifolds, see Wall, [4].

The Proof of Theorem 3. We may again assume $H_{*}\left(L, K_{0}\right)=0$, $* \neq n, n+1$. $L$ may be described as $K_{0} \times I \cup n, n+1$-handles. Let $D_{j}^{+}$be the cores of the $n$-handles. Disks $D_{j}^{-} \rightarrow K_{0} \times I$ may be chosen so that $f_{\#}\left[D_{j}^{+} \cup D_{j}^{-}\right]=0 \in \pi_{n}(M)$ as $f_{\#}: \pi_{n-1}\left(K_{0}\right) \rightarrow \pi_{n-1}(M)$ is an isomorphism and $f_{\#}: \pi_{n}\left(K_{0}\right) \rightarrow \pi_{n}(M)$ is surjective. Let $H$ be the level set of $L$ after the $n$-handles have been attached. The preceding statement implies that $H$ is obtained from $K_{0}$ by a sequence of surgeries on $(n-1)$-spheres, $\partial D_{j}^{-}$, trivialized by some null-homotopy $\left(D_{j}^{-}\right)$in $K_{0} \times I$. By general position $\left\{\partial D_{\jmath}^{-}\right\}$is isotopically trivial (we check $(n-1)+1<\frac{1}{2}(2 n+1)$ ). Therefore, $H \stackrel{\text { diff }}{\cong} K_{0} \#_{j}\left(S^{n} \times S^{n}\right)_{J}$. By turning $L$ upside down, we obtain $H \cong \#_{k}\left(S^{n} \times S^{n}\right)_{k}$. This proves Theorem 3 .

\section{REFERENCES}

1. W. Browder, Surgery on simply connected manifolds, Springer-Verlag, 1972.

2. M. Kato and Y. Matsumoto, Simply connected surgery of submanifolds in co-dimension 2, I, J. Math. Soc. Japan, 24 (72), 586-608.

3. M. Kervaire and J. Milnor, Groups of homotopy spheres I, Ann. Math., 77 (1963), 504-537.

4. C. T. C. Wall, On simply connected 4-manifolds, J. London Math. Soc., 39 (1964), 141-149.

Received May 19, 1975. Partially supported by NSF Grant.

INSTITUTE FOR ADVANCED STUdy 



\section{PACIFIC JOURNAL OF MATHEMATICS}

\section{EDITORS}

RICHARD ARENS (Managing Editor)

University of California

Los Angeles, California 90024

\section{J. Dugundu}

Department of Mathematics University of Southern California Los Angeles, California 90007

D. Gilbarg and J. Milgram Stanford University Stanford, California 94305

\section{ASSOCIATE EDITORS}
E. F. BECKENBACH
B. H. NeumanN
F. WOLF
K. YoSHIDA

\section{SUPPORTING INSTITUTIONS}

UNIVERSITY OF BRITISH COLUMBIA CALIFORNIA INSTITUTE OF TECHNOLOGY

UNIVERSITY OF CALIFORNIA

MONTANA STATE UNIVERSITY

UNIVERSITY OF NEVADA

NEW MEXICO STATE UNIVERSITY

OREGON STATE UNIVERSITY

UNIVERSITY OF OREGON

OSAKA UNIVERSITY

\author{
UNIVERSITY OF SOUTHERN CALIFORNIA \\ STANFORD UNIVERSITY \\ UNIVERSITY OF HAWAII \\ UNIVERSITY OF TOKYO \\ UNIVERSITY OF UTAH \\ WASHINGTON STATE UNIVERSITY \\ UNIVERSITY OF WASHINGTON \\ AMERICAN MATHEMATICAL SOCIETY
}

The Supporting Institutions listed above contribute to the cost of publication of this Journal, but they are not owners or publishers and have no responsibility for its contents or policies.

Mathematical papers intended for publication in the Pacific Journal of Mathematics should be in typed form or offset-reproduced (not dittoed), double spaced with large margins. Underline Greek letters in red, German in green, and script in blue. The first paragraph or two must be capable of being used separately as a synopsis of the entire paper. Items of the bibliography should not be cited there unless absolutely necessary, in which case they must be identified by author and Journal, rather than by item number. Manuscripts, in duplicate, may be sent to any one of the four editors. Please classify according to the scheme of Math. Reviews, Index to Vol. 39. All other communications should be addressed to the managing editor, or Elaine Barth, University of California, Los Angeles, California, 90024.

100 reprints are provided free for each article, only if page charges have been substantially paid. Additional copies may be obtained at cost in multiples of 50 .

The Pacific Journal of Mathematics is issued monthly as of January 1966. Regular subscription rate: $\$ 72.00$ a year (6 Vols., 12 issues). Special rate: $\$ 36.00$ a year to individual members of supporting institutions.

Subscriptions, orders for back numbers, and changes of address should be sent to Pacific Journal of Mathematics, 103 Highland Boulevard, Berkeley, California, 94708.

PUBLISHED BY PACIFIC JOURNAL OF MATHEMATICS, A NON-PROFIT CORPORATION

Printed at Jerusalem Academic Press, POB 2390, Jerusalem, Israel.

$$
\begin{gathered}
\text { Copyright } 1976 \text { Pacific Journal of Mathematics } \\
\text { All Rights Reserved }
\end{gathered}
$$




\section{Pacific Journal of Mathematics}

Vol. 62, No. 2

February, 1976

Allan Russell Adler and Catarina Isabel Kiefe, Pseudofinite fields, procyclic

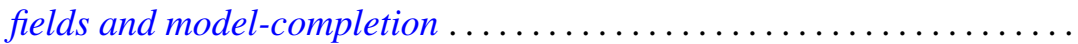

Christopher Allday, The stratification of compact connected Lie group

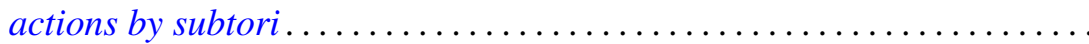

Martin Bartelt, Commutants of multipliers and translation operators .......

Herbert Stanley Bear, Jr., Ordered Gleason parts ..................

James Robert Boone, On irreducible spaces. II .....................

James Robert Boone, On the cardinality relationships between discrete

collections and open covers ............................

L. S. Dube, On finite Hankel transformation of generalized functions .......

Michael Freedman, Uniqueness theorems for taut submanifolds . . . . . . . . .

Shmuel Friedland and Raphael Loewy, Subspaces of symmetric matrices

containing matrices with a multiple first eigenvalue .............

Theodore William Gamelin, Uniform algebras spanned by Hartogs



James Guyker, On partial isometries with no isometric part ............

Shigeru Hasegawa and Ryōtarō Satō, A general ratio ergodic theorem for

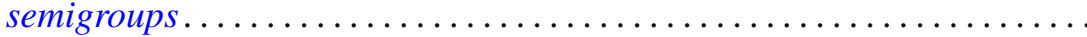

Nigel Kalton and G. V. Wood, Homomorphisms of group algebras with norm less than $\sqrt{2}$.

Thomas Laffey, On the structure of algebraic algebras...

Will Y. K. Lee, On a correctness class of the Bessel type differential operator $S_{\mu}$

Robert D. Little, Complex vector fields and divisible Chern classes ....

Kenneth Louden, Maximal quotient rings of ring extensions . .

Dieter Lutz, Scalar spectral operators, ordered $l^{\rho}$-direct sums, and the

counterexample of Kakutani-McCarthy . .

Ralph Tyrrell Rockafellar and Roger Jean-Baptiste Robert Wets, Stochastic

convex programming: singular multipliers and extended duality

singular multipliers and duality.

Edward Barry Saff and Richard Steven Varga, Geometric overconvergence of rational functions in unbounded domains ..........

Joel Linn Schiff, Isomorphisms between harmonic and P-harmonic Hardy

spaces on Riemann surfaces.

Virinda Mohan Sehgal and S. P. Singh, On a fixed point theorem of

Krasnoselskii for locally convex spaces.

Lewis Shilane, Filtered spaces admitting spectral sequence operations

Michel Smith, Generating large indecomposable continua . 